Journal home page: http://www.sciencedirect.com/science/journal/09977538

A non-linear study of a cracked rotor

European Journal of Mechanics - A/Solids, Volume 26, Issue 1, January-February 2007, Pages 152-170

J.-J. Sinou and A.W. Lees

\title{
A NON-LINEAR STUDY OF A CRACKED ROTOR
}

\author{
J-J. Sinou ${ }^{1 *}$ and A.W. Lees ${ }^{2}$ \\ ${ }^{1}$ Laboratoire de Tribologie et Dynamique des Systèmes UMR CNRS 5513, \\ Ecole Centrale de Lyon, 36 avenue Guy de Collongue, 69134 Ecully Cedex, France. \\ jean-jacques.sinou@ec-lyon.fr \\ ${ }^{2}$ School of Engineering, University of Wales Swansea, \\ Singleton Park, Swansea SA2 8PP, Wales, UK. \\ a.w.lees@swansea.ac.uk
}

\begin{abstract}
The influence of the presence of transverse cracks in a rotating shaft is analysed. The paper addresses the influence of crack opening and closing on dynamic response during operation. The evolution of the orbit of the cracked rotor near half and one-third of the first critical speed is investigated. The dynamic response of the rotor with a breathing crack is evaluated by expanding the changing stiffness of the crack as a truncated Fourier series and then using the Harmonic Balance Method. This method is applied to compute various parametric studies including the effects of the crack depth and location on the dynamic of a crack rotor. The evolution of the first critical speed, associated amplitudes at the critical speed and half of the critical speed, and the resulting orbits during transient operation are presented and some distinguishing features of a cracked rotor are examined.
\end{abstract}

Keywords: rotor, breathing crack, non-linear dynamic, crack depth.

\section{INTRODUCTION}

One form of damage that can lead to catastrophic failure is an undetected crack in a shaft and in recent years significant effort has been devoted to the detection of transverse cracks in shafts [1-31]. This problem may be approached by observing the vibrational behaviour of rotor systems with a crack and one of the advantages of vibration measurement is that the detection of a crack can be carried out non invasively. In this paper a theoretical model is used to identify the characteristics of a system in the presence of a transverse crack. At this point it is necessary to define some terminology: if a rotor has a crack, this crack may remain open or closed during the rotors motion, or it may open and close during different parts of the cycle. This latter case is referred to by some authors as a 'breathing crack', but it this paper, the rather more accurate term 'active crack' is used. 
Generally, two different approaches are attempted to identify the presence of a crack in rotating structures. The first approach is based on the fact that the presence of a crack in rotating shaft reduces the stiffness of the structure, hence reducing the natural frequencies of the original uncracked shaft [30,31]. The second approach takes into account the influence of a transverse active crack on the response of a rotor model [924, 28-29]. The dynamic behaviour of the cracked rotor and the evolution of the orbit over time at around one-half of the resonance appear to be the classical signature for detecting the presence of an active crack $[17,18,31]$.

In this paper, a simple model is presented to describe the effect of an active crack. The Harmonic Balance Method is then applied to this model. This non-linear method is applied in order to save time and to be able to undertake parametric numerical studies. Finally, the dynamic behaviour due to the presence of the breathing crack is investigated, particularly the behaviour of the $2 \mathrm{X}$ and $3 \mathrm{X}$ harmonic component of the system and the evolution of the orbit near one-half and one-third of the first critical speed. Parametric studies considering the influences of the crack depth and location will be investigated in order to examine the possibility of detecting the presence of a crack even if the crack depth is small or the crack is situated in an unfavourable position. The effect of crack depth and location on first critical speed, the associated amplitudes at the critical speed and at half of the critical speed, and the resulting orbits during transient operation are presented and discussed.

\section{MODELING OF THE CRACK ROTOR}

In this section, the model of the rotor is introduced.

\subsection{MODEL OF THE ROTOR}

The system under study is illustrated in Figure 1. The rotor is composed of a rotor shaft with one disc at the mid-span. The rotor shaft is modelled and discretized into 10 Timoshenko beam finite elements with four degrees of freedoms at each node [32, 33] and a constant circular cross-section.

As illustrated in Figure 1, the nodal displacement of a beam element is defined by

$$
\delta=\left[\begin{array}{llllllll}
v_{1} & w_{1} & \theta_{1} & \psi_{1} & v_{2} & w_{2} & \theta_{2} & \psi_{2}
\end{array}\right]^{T}
$$

The expression of the mass matrix $\mathbf{M}^{e}=\mathbf{M}_{1}^{e}+\mathbf{M}_{2}^{e}$ (the summation of the translational and rotary mass matrices), the stiffness matrix $\mathbf{K}^{e}$, the skew-symmetric gyroscopic matrix $\mathbf{G}^{e}$ and the damping matrix $\mathbf{C}^{e}$ can be written by

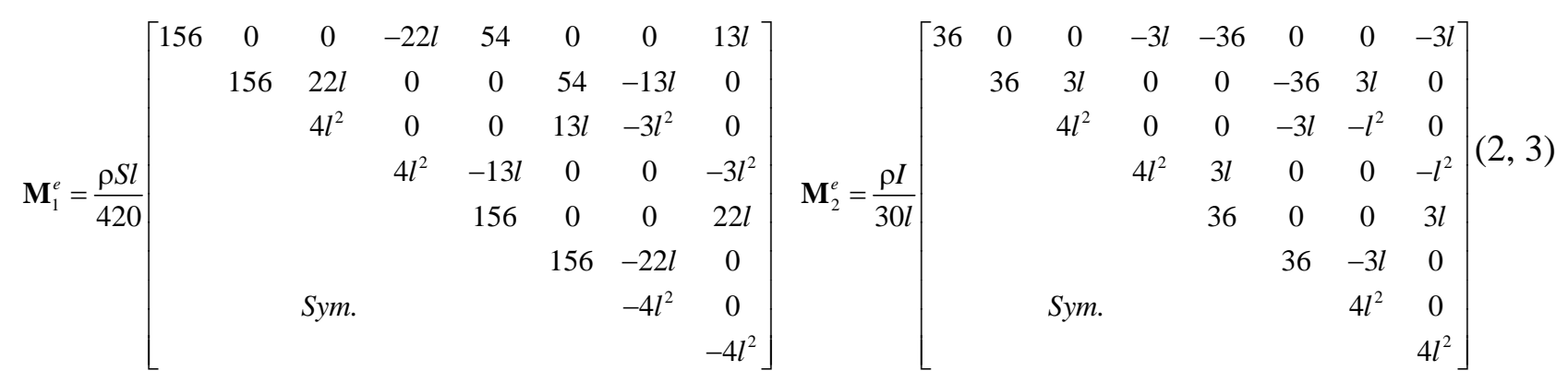




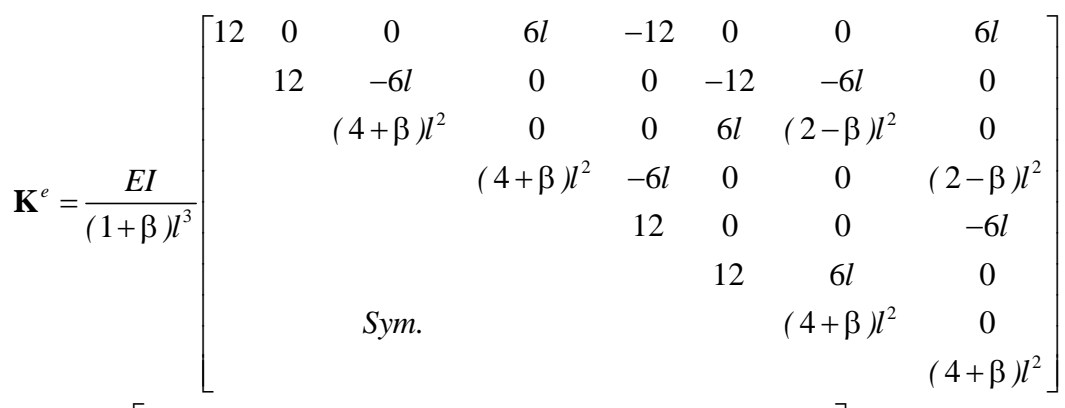

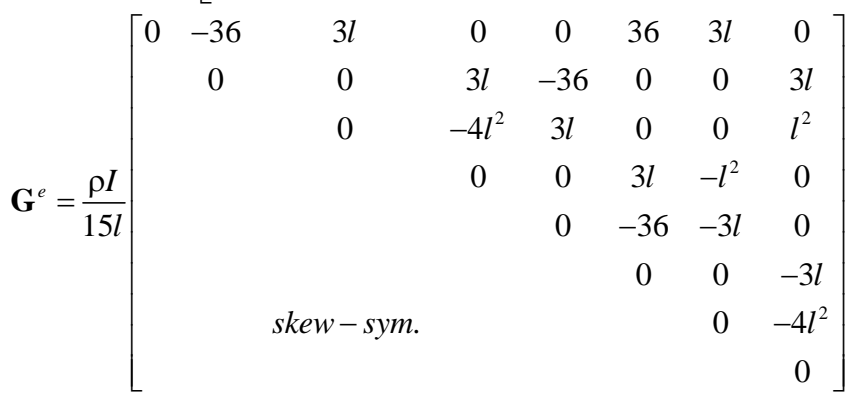

and $\mathbf{C}^{e}=\alpha \mathbf{K}^{e} . E$ and $\rho$ are the Young's modulus of elasticity and density of the rotor shaft. $I$ is the second moment of area about any axis perpendicular to the rotor axis. The shear coefficient is given by $G=\frac{E}{2(1+v)}$ with the shear modulus $\beta=\frac{12 E I}{G S_{r} l^{2}} \cdot v$ is Poisson's ratio and $S_{r}$ is the reduced area of the cross section. $\alpha$ is a proportional factor to stiffness.The mass and gyroscopic matrices $\mathbf{M}_{d}$ and $\mathbf{G}_{d}$ for the disk corresponding to the degree-of-freedom $\left[\begin{array}{llll}v & w & \theta & \psi\end{array}\right]^{T}$ are given by

$$
\mathbf{M}_{d}=\left[\begin{array}{cccc}
m_{d} & 0 & 0 & 0 \\
0 & m_{d} & 0 & 0 \\
0 & 0 & I_{d} & 0 \\
0 & 0 & 0 & I_{d}
\end{array}\right] \quad \text { and } \quad \mathbf{G}_{d}=\omega\left[\begin{array}{cccc}
0 & 0 & 0 & 0 \\
0 & 0 & 0 & 0 \\
0 & 0 & 0 & -I_{p} \\
0 & 0 & I_{p} & 0
\end{array}\right]
$$

where. $m_{d}$ is the mass of the disk. and $\left(I_{p}, I_{d}\right)$ are the polar moment of inertia about the rotor axis and the diametral moment of inertia about any axis perpendicular to the rotor axis respectively. $\omega$ defines the rotational speed of the rotor. Finally, $\mathbf{Q}^{e}$ and $\mathbf{W}^{e}$ defining the vector of gravity force and imbalance force are given by (for the degree-of-freedom $\left[\begin{array}{llll}v & w & \theta & \psi\end{array}\right]^{T}$ )

$$
\mathbf{W}^{e}=\left[\begin{array}{c}
m_{e} d_{e} \omega^{2} \cos (\omega t+\phi) \\
m_{e} d_{e} \omega^{2} \sin (\omega t+\phi) \\
0 \\
0
\end{array}\right] \quad \text { and } \quad \mathbf{Q}^{e}=\left[\begin{array}{c}
0 \\
-m g \\
0 \\
0
\end{array}\right]
$$

where $m_{e}$ and $d_{e}$ are the mass unbalance and the eccentricity. $\phi$ defines the initial angular position with respect to the z-axis. $m$ is the mass for each element.

Finally, the discrete bearing stiffness coefficients are placed at the corresponding degrees of freedom and the equation of motion for the complete rotor system is defined as follows

$$
\mathbf{M} \ddot{\mathbf{x}}+(\mathbf{C}+\omega \mathbf{G}) \dot{\mathbf{x}}+\mathbf{K x}=\mathbf{Q}+\mathbf{W}
$$

where $\mathbf{M}$ and $\mathbf{G}$ are the mass and gyroscopic matrices including mass and gyroscopic matrices of the shaft and rigid discs. $\mathbf{C}$ and $\mathbf{K}$ are the external damping and stiffness matrices of the shaft. $\mathbf{Q}$ and $\mathbf{W}$ define the vector of gravity force and imbalance force for the complete rotor system. 


\subsection{MODEL OF OPENING AND CLOSING CRACK}

The modelling of transverse crack as explained in [31] is briefly presented here. In a cracked rotor, at the crack location, the part of the cross section which is cracked is not capable of supporting tensile stress. Depending on the orientation of the rotor, the crack is in a compression zone or in a tension zone and the shaft is more or less stiff. To accurately predict the dynamic response of the rotor system with an active crack, an appropriate crack model is essential. Many researchers have studied this problem and proposed to obtain the localized additional flexibility due to the crack by considering the strain energy density function and the associated crack stress concentration factor $[9,14,15]$.

Mayes and Davies [1-2] demonstrated that a transverse crack in a rotor shaft might be represented by the reduction of the second moment of area $\Delta I$ of the element at the location of the crack. By using Rayleigh's method, they established that the change in $\Delta I$ satisfied [2]

$$
\frac{\Delta I / I_{0}}{1-\Delta I / I_{0}}=\frac{R}{l}\left(1-v^{2}\right) F(\mu)
$$

where $I_{0}, R, l, v, \mu$, and $F(\mu)$ are the second moment of area, the shaft radius, the length of the section, the Poisson's ratio, the non-dimensional crack depth, and the compliance function (as a function of non-dimensional crack depth) respectively. Note that $\mu=a / R$ where $a$ defines the crack depth, as indicated in Figure 1. Mayes and Davies demonstrated that $F(\mu)$ is the fractional change in the second moment of area measured at the crack face by considering a series of experimental tests for various transverse crack [2]. It may be noted that there are two values of $F(\mu)$ for a given transverse crack, one for each of the orthogonal directions in the plane of the crack.

Then, the cross section of the rotor shaft at the location of the crack has asymmetric area moments inertia about the neutral axis of bending, as illustrated in Figure 1. In the case of an uncracked shaft, the neutral axes of bending are defined by the $X$ and $Y$ axes. Using the expressions given in the appendix of reference [31], the stiffness matrix due to the transverse crack $\mathbf{K}_{\text {crack }}$ can be obtained at the crack location, by using standard finite elements

$$
\mathbf{K}_{\text {crack }}=\frac{E}{l^{3}}\left[\begin{array}{cccccccc}
12 I_{X} & 0 & 0 & 6 l I_{X} & -12 I_{X} & 0 & 0 & 6 l I_{X} \\
& 12 I_{Y} & -6 l I_{Y} & 0 & 0 & -12 I_{Y} & -6 l I_{Y} & 0 \\
& & (4+\beta) l^{2} I_{Y} & 0 & 0 & 6 l I_{Y} & (2-\beta) l^{2} I_{Y} & 0 \\
& & & (4+\beta) l^{2} I_{X} & -6 l I_{X} & 0 & 0 & (2-\beta) l^{2} I_{X} \\
& & & & 12 I_{X} & 0 & 0 & -6 l I_{X} \\
& & & & & 12 I_{Y} & 6 l I_{Y} & 0 \\
& & & & & & (4+\beta) l^{2} I_{Y} & 0 \\
& & & & & & & (4+\beta) l^{2} I_{X}
\end{array}\right]
$$

When the rotor is cracked, and the crack is active, the opening and closing behaviour due to the rotor rotation and shaft self-weight results in a time dependent stiffness with time and angle. Many researchers have proposed models for breathing crack . However, Penny and Friswell [18] demonstrated that for structural health monitoring using low frequency vibration, simple models of the crack are adequate and sufficient for the prediction of the dynamic behaviour of a rotor with an active crack, as well as the predicted whirl orbit at the steady-state $2 \times$ response.

One of the usual models of a crack is that of Mayes and Davies [1-2] which has been used by many other researchers where the opening and closing of the crack was described by a cosine function by assuming that the gravity force is much greater that the imbalance force, the function describing the breathing crack 
may given by $f(t)=\frac{1}{2}(1-\cos (\omega t))$ where $\omega$ is the rotational speed of the rotor. It may be observed that the crack is totally closed for $f(t)=0$, and full open for $f(t)=1$.

\subsection{MODEL OF THE COMPLETE ROTOR}

After assembling the different shaft elements, adding the modelling of the rigid discs and bearing, the complete rotor model with a crack is given by

$$
\mathbf{M} \ddot{\mathbf{x}}+(\mathbf{C}+\omega \mathbf{G}) \dot{\mathbf{x}}+\left(\mathbf{K}-f(t) \mathbf{K}_{\text {crack }}\right) \mathbf{x}=\mathbf{Q}+\mathbf{W}
$$

where $\ddot{\mathbf{x}}, \dot{\mathbf{x}}$, and $\mathbf{x}$ are the acceleration, velocity and displacement of the degree-of freedom of the cracked rotor system. $\mathbf{M}, \mathbf{C}, \mathbf{G}$ and $\mathbf{K}$ are the mass, damping, gyroscopic and stiffness matrices, respectively. $\mathbf{Q}$ and $\mathbf{W}$ define the vector of gravity force and imbalance force, respectively. $\mathbf{K}_{\text {crack }}$ is the stiffness matrix due to the crack and $f(t)$ the function representing the opening/closing effect. All the values of the parameters are given in Table 1.

Whilst it is not immediately obvious, the equation (12) given above is non-linear. To a first approximation, a cracked rotor may be treated as a linear system with time varying coefficients, a rotor with either a large crack or a large imbalance will require a full non-linear treatment. The non-linear term arises because substantial deflection will give rise to local axial stretching and this effect the position of the neutral axis of any specified cross section of the rotor.

\section{HARMONIC BALANCE METHOD}

One of the classical approach in order to obtain the response of rotor system is the numerical integration procedure. However, this approach may be rather expensive and requires considerable resources both in terms of computation time and data storage. So the Harmonic Balance Method that is one of the most wellknown approximation technique [31, 34] will be briefly explained and applied for this study. We do not claim to make an important contribution in this section. The only purpose is to give an overview of the harmonic balance method that underlies this paper. We refer the interested reader to [31] for an extensive overview of the harmonic balance method.

Moreover, in the field of rotating machinery, the system behavior is calculated for various operational speed of interest while all other parameters are kept constant. In this case, predictor can be used in order to estimate the response of the rotor system when the rotational speed increases. The Lagrangian extrapolation method [31] is applied in order to obtain the estimated point on the solution branch. The rotor system defined in equation (12) can be written as

$$
\mathbf{M} \ddot{\mathbf{x}}+\mathbf{D}(\omega) \dot{\mathbf{x}}+\mathbf{K x}=\mathbf{F}(\mathbf{x}, \omega, t) \quad \text { with } \quad \mathbf{F}(\mathbf{x}, \omega, t)=f(t) \mathbf{K}_{\text {crack }} \cdot \mathbf{x}+\mathbf{g}(\mathbf{x}, \omega, t)
$$

$\mathbf{M}$ and $\mathbf{K}$ are the mass and the stiffness matrices, whilst $\mathbf{D}$ is a term involving both the damping and gyroscopic matrices. $\mathbf{F}$ and is the vector containing the non-linear expressions due to the breathing crack $f(t) \mathbf{K}_{\text {crack }} . \mathbf{x}$ and the vector for the imbalance and gravity force $\mathbf{g}(\mathbf{x}, \omega, t)$. If the rotor system is subjected to periodic excitation, the response of the right-hand side of the previous equation $\mathbf{F}(\mathbf{x}, \omega, t)$ and the required solution of the rotor system $\mathbf{x}(t)$ can be approximated by a finite Fourier series

$$
\mathbf{x}(t)=\sum_{n=0}^{m}\left(\mathbf{A}_{n} \cos (n \omega t)+\mathbf{B}_{n} \sin (n \omega t)\right) \text { and } \mathbf{F}(t)=\sum_{n=0}^{m}\left(\mathbf{S}_{n} \cos (n \omega t)+\mathbf{T}_{n} \sin (n \omega t)\right)
$$

where $\omega$ is the fundamental frequency given by $\omega=2 \pi / T . \mathbf{S}_{n}$ and $\mathbf{T}_{n}$ (with $0 \leq n \leq m$ ) is an implicit function of $\mathbf{V}=\left[\begin{array}{llllll}\mathbf{A}_{0} & \mathbf{A}_{1} & \mathbf{B}_{1} & \cdots & \mathbf{A}_{m} & \mathbf{B}_{m}\end{array}\right]$ that is a $(2 m+1) \times r$ matrix of the unknown coefficients of the truncated Fourier series (where $r$ defines the number of degree-of-freedom of the rotor system). As 
explained by Cameron and Griffin [35], the determination of the coefficients $\mathbf{U}=\left[\begin{array}{llllll}\mathbf{S}_{0} & \mathbf{S}_{1} & \mathbf{T}_{1} & \cdots & \mathbf{S}_{m} & \mathbf{T}_{m}\end{array}\right]$ can be easily calculated by considering the process of switching between the frequency and time domains by using a Discrete Fourier transform DFT [31]

$$
\left[\begin{array}{llllll}
\mathbf{A}_{0} & \mathbf{A}_{1} \mathbf{B}_{1} \cdots & \mathbf{A}_{m} & \mathbf{B}_{m}
\end{array}\right] \stackrel{\mathrm{DFT}^{-1}}{\longrightarrow} \mathbf{x}(t) \rightarrow \mathbf{F}(t) \stackrel{\mathrm{DFT}}{\longrightarrow}\left[\mathbf{S}_{0} \mathbf{S}_{1} \mathbf{T}_{1} \cdots \mathbf{S}_{m} \mathbf{T}_{m}\right]
$$

Substituting the previous truncated Fourier expressions in the dynamic equation yields a set of $m \times r$ linear equations. By equating coefficients for the cosine and sine terms, one obtains a set of $(2 m+1) \times r$ simultaneous equations

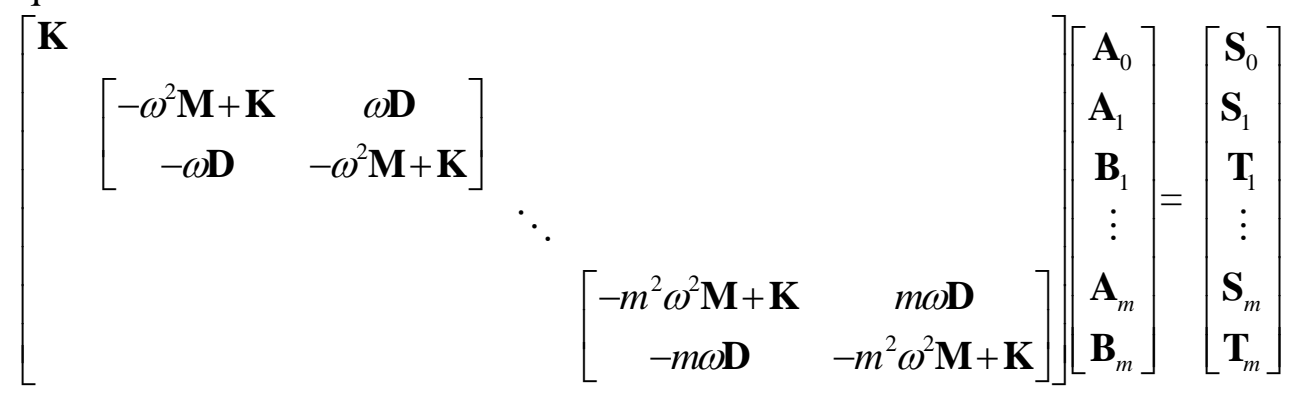

The $(2 m+1) \times r$ unknown coefficients $\mathbf{V}=\left[\begin{array}{llllll}\mathbf{A}_{0} & \mathbf{A}_{1} & \mathbf{B}_{1} & \cdots & \mathbf{A}_{m} & \mathbf{B}_{m}\end{array}\right]$ can be determined uniquely. We refer the interested reader to [31] for an extensive overview of the non-linear analysis and harmonic balance method.

\section{NUMERICAL RESULTS}

In this section, the influence of a deep crack (with the non-dimensional crack depth equal to $\mu=1$ ) situated at the middle of the shaft is investigated. The effects of the non-dimensional crack depth and crack position are considered as a possible tool for the detection of cracks in rotating systems.

\subsection{DYNAMIC BEHAVIOUR OF A ROTOR WITH A DEEP CRACK AT THE MIDDLE}

Figure 2 shows the horizontal and vertical steady state responses of the uncracked rotor and the rotor with an active crack ( $\mu=1$ at the centre span of the shaft). The horizontal and vertical displacements are given for all the transversal nodes of the shaft. For the uncracked rotor, the vertical and horizontal displacements indicate the presence of the first critical speed around 310rad/s. For the cracked rotor, it clearly appears that the presence of the crack the $2 \mathrm{X}$ resonance is predicted for the horizontal and vertical displacements when the running speed is approximately one-half of the first critical speed (around 150-155 rad/s). Moreover, the 3X resonances of the system response is clearly identified at one-third of the first critical speed for the vertical displacement (around 100-110 rad/s).

These previous observations and comparison between the cracked and uncracked rotors are the first step for the detection of crack in rotating systems. However, the diagnosis of the presence of a crack in rotating machinery based only on the appearance of a harmonics response at half or/and one-third the first critical speed in the spectrum may be misleading: it is, in fact, merely a diagnosis of non-linearity. As explained by Sinou and Lees [31], one of the features to detect the presence of a transverse crack in a rotating shaft is the use of the evolution of the orbit over time at around one-half of the critical speeds. When the rotating speed of the cracked rotor is passing through half of the first critical speed, the orbit changes firstly from a simple loop to a double loop, as illustrated in Figure 3 (from $\omega=150 \mathrm{rad} / \mathrm{s}$ to $\omega=155 \mathrm{rad} / \mathrm{s}$ ). Then, one distortion in the orbit appears (around $\omega=156 \mathrm{rad} / \mathrm{s}$ ) and the shape of the orbit changes finally to a simple loop containing a small inside loop as illustrated in Figure 3 (from $\omega=157 \mathrm{rad} / \mathrm{s}$ to $\omega=160 \mathrm{rad} / \mathrm{s}$ ). These observations form the signature of the presence of a crack indicating the change in amplitude and phase at half any resonance speed, and is also a characteristic for signals containing two vibration components with 
the same direction of precession. Moreover, when the rotating speed passes through one-third of the first critical speed, the change of the shape of the orbit may be used in order to detect the presence of a crack. As indicated in Figure 4, the shape of the orbit changes from a simple loop to a triple loop. Finally, all these changes in the shape of orbits may be used in order to detect the presence of crack during the transient operation of machinery. However, these changes of the behaviour of the rotor system due to the presence of a crack have been studied for a deep crack $(\mu=1)$ situated at the mid-span of the shaft so that the system is sensitive to the crack. It is important at this stage to assess the sensitivity of the response to both crack depth and (axial) position.

\subsection{INFLUENCE OF CRACK DEPTH AND CRACK POSITION}

The influences of the non-dimensional crack depth and crack position are investigated for $\mu=0$ to $\mu=1$ and a crack situated at the various nodes of the rotor shaft. The largest crack considered is the non-dimensional depth $\mu=1$, which corresponds to the case of half the area of the cross-section is missing due to the transverse crack.

Figures 5 show the evolution of the vertical amplitudes around the first critical speed at the middle of the shaft versus the crack depth and crack position. It may be observed that increasing the crack depth decreases the value of the first critical speed for all the position cracks. Moreover, if the crack is situated at the middle of the shaft, the first critical speed decreases (for the same value of the crack depth). These results may be clearly interpreted as the contribution of the reduced stiffness which changes the system natural frequencies, resulting from the presence of the crack.

The percentage changes in the first critical speed with the non-dimensional crack depth and the location of the crack are presented in Figures 6 for the vertical and horizontal displacements. The percentage change in the first critical speed is obtained by comparing the different values for a cracked rotor with the critical speed of the uncracked rotor. The highest changes in the value of the first critical speed occur in the vertical displacement due to the orientation of the crack and the shaft self-weight. As explained previously, these results may be considered as those obtained from the evolution of the natural frequencies of the rotor with the non-dimensional crack depth and crack position which are the common first step in the diagnosis of a crack [31].

Figures 7 illustrate the evolution of the maximum vertical and horizontal amplitudes at the first critical speed. The value of the critical speed varies with the crack depth and crack location. The maximum vertical and horizontal amplitudes are drastically affected by the variation of the crack depth and crack location. Moreover, the evolution of the vertical and horizontal maximum amplitudes versus the crack depth and crack position are very different. As illustrated in Figure 7, the horizontal maximum amplitude growths gradually with the non-dimensional crack depth. For the vertical maximum amplitude, the evolution is stronger when the non-dimensional crack depth reaches 1 .These results may be very interesting for the detection of the presence of a crack and to evaluate the crack depth and crack location of the rotor system.

Figures 8 illustrate the evolution of the vertical amplitudes for the middle of the rotor shaft around half of the first critical speed. In these cases, the changes of the value of the maximum amplitudes clearly appear: increasing the non-dimensional crack depth decrease the rotating speed where the maximum amplitude is observed, and considering a crack near the middle of the rotor shaft decrease also the rotating speed value of the maximum amplitude. These results are only due to the variation of the value of first critical speed with the crack depth and crack location (i.e. the reduced stiffness which changes the system natural frequencies, resulting from the presence of the crack). Moreover, it may be observed that the nondimensional crack depth and crack position affect the value of the maximum vertical and horizontal amplitude when the rotating speed passes through half the first critical speed, as illustrated in Figures 9. The amplitude of the vertical and horizontal responses is shown to increase in magnitude as the crack depth increases. This phenomenon is due to the increased asymmetry as crack depth increases. 
The evolution of the orbits at the middle of the rotor shaft are represented versus the non-dimensional crack depth and crack position in Figure 10 and 11. For the results presented in Figure 10, the crack is situated at the mid-span of the rotor shaft and for those presented in Figure 11, the non-dimensional crack depth is equal to 1 . As indicated in Figure 11, if the non-dimensional crack depth is greater than 0.5, the "outside-inside loop" phenomena and the distortion of the orbit shape is clearly observed. So, if the nondimensional crack depth is important, it will be possible to detect the presence of a crack by considering the orbit evolution passing through half the first critical speed. If not in the contrary case, the consideration of the evolution of the maximum vertical and horizontal amplitudes at half the critical speed and the evolution of the value of the critical speed and the associated amplitudes may be used to detect the presence of a crack. These considerations and observation could also provide crack diagnostic information. Moreover, the orbit evolutions due to the location of the crack indicate that the "outside-inside loop" phenomena may not be observed if the crack is situated at one end of the rotor shaft .

Finally, the evolutions of the maximum amplitudes and the associated values of the rotating speed around one-third of the first critical speed could be investigated in order to detect the presence and signature of a crack as previously explained for a crack of non-dimensional depth $\mu=1$ (Figure 4). However, it appears very difficult to observe clearly the effect of a crack if its depth is smaller than 0.9 and 1 , and if the crack is not situated near the middle of the shaft, as illustrated in Figures 12 for the vertical amplitudes. Furthermore the horizontal amplitudes are less sensitive to the crack and hence detection is more difficult.

\section{CONCLUSION}

This study has demonstrated that the introduction of a deep breathing crack induced the $2 \mathrm{X}$ and $3 \mathrm{X}$ harmonic component of the system response. The behaviour of the $2 \mathrm{X}$ harmonic component of the system response increases in magnitude when the crack depth increases. Moreover, the primary response characteristic resulting from the changes in the non-linear dynamical behaviour of the rotor system through half resonance speeds appears to be the characteristic signature for detecting the presence of a crack rotor. Indeed, the distortion of the orbit, and formation of a double loop and inside loop in the orbit could be considered as one of the most practical indicators of the presence of a transversal crack for health monitoring purposes.

The non-dimensional crack depth and crack location should strongly influence the detection of a crack. If the signature for detecting the presence of a crack rotor my not be based of the "outside-inside loops" phenomena, the evolution of the maximum vertical and horizontal amplitudes at half the first critical speed, and the changes of the values of the first critical speed and the associated vertical and horizontal maximum amplitudes should be used to detect a breathing crack: an increase in the amplitude of the response, as well as a decrease in the rotor speed at which the response is maximum around half of the first critical speed, are characteristics of the presence of a transverse rotor crack.

Finally, both the orbit evolution at half of the first critical speed, and the magnitude of the response at at the first critical speed and at half of the first critical speed may be considered as the unique characteristics of the system responses with a breathing crack and also served as target observations for monitoring rotating machinery.

\section{REFERENCES}

1. W.G.R. Davies, and I.W. Mayes, The Vibrational Behaviour of a Multi-Shaft, Multi-Bearing System in the Presence of a Propagating Transverse Crack, Transactions of the ASME Journal of Vibration, Acoustics, Stress, and Reliability in Design, 106, 1984, 146-153. 
2. I.W. Mayes,. and W.G.R. Davies, Analysis of the Response of a Multi-Rotor-Bearing System Containing a Transverse Crack in a Rotor, Transactions of the ASME Journal of Vibration, Acoustics, Stress, and Reliability in Design, 106, 1984, 139-145.

3. J. Wauer, Modelling and formulation of equations for cracked rotating shafts, Int. J. Solids Structures, 26(8), 1990, 901-914.

4. J. Wauer, Dynamics of Cracked Rotors: Literature Survey, Applied Mechanics Review, 43, 1990, 1317.

5. D.E. Bently, C.T. Hatch C.T., and B. Grissom, Fundamentals of Rotating Machinery Diagnostics, Bently Pressurized Bearing Press, 2002.

6. D.E. Bently, Vibration Analysis Techniques for Detecting and Diagnosing Shaft Cracks, Orbit, Bently Nevada Corporation, USA, 1986, 18-23.

7. A.D. Dimarogonas, Vibration of Cracked Structures: a State of the Art Review, Engineering Fracture Mechanics., 55, 1996, 831-857

8. A.D. Dimarogonas and G. Massouros, Torsional Vibration of a Shaft with a Circumferential crack, Engineering Fracture Mechanics, 15(3-4), 1980, 439-444.

9. C.A. Papadopoulos and A.D. Dimarogonas, Coupled Longitudinal and Bending Vibrations of a Rotating Shaft with an Open Crack, Journal of Sound and Vibration, 117(1), 1987, 81-93.

10. A.S. Sekhar, and B.S. Prabhu, Condition Monitoring of Cracked Rotors Through Transient Response Mechanism and Machine Theory, 33(8), 1998, 1167-1175.

11. A.S. Sekhar and B.S. Prabhu, Crack Detection and Vibration Characteristics of Cracked Shafts, Journal of Sound and Vibration, 157(2), 1992,. 375-381.

12. A.S. Sekhar and A.S. Rao, Crack Versus Misalignment in Rotor-Coupling Bearing System, Machine Vibration, 5, 1996, 179-188.

13. S. Prabhakar, A.S. Sekhar, and A.R. Mohanty, Transient Lateral Analysis of a Slant-Cracked Rotor Passing Through its flexural critical Speed, Mechanisl and Machine Theory, 37,2002, 1007-1020.

14. A.K. Darpe, A. Chawla and K. Gupta, Analysis of the Response of a Cracked Jeffcott Rotor to Axial Excitation, Journal of Sound and Vibration, 249(3), 2002, 429-224.

15. M-C. Wu and S-C. Huang, Vibration and Crack Detection of a Rotor with Speed-Dependent Bearings International Journal of Mechanical Science, 40(6), 1998, 545-555.

16. N. Bachschmid, G. Diana, and B. Pizzigoni The Influence of Unbalance on Cracked Rotors, Vibrations of Rotating Machinery, Institution of Mechanical Engineers, 1984, 193-198.

17. M.I. Friswell, and J.E.T.P Penny, Crack Modelling for Structural Health Monitoring, International Journal of Structural Health Monitoring, 1(2), 2002, 139-148.

18. J.E.T.P. Penny, and M.I. Friswell Simplified Modelling of Rotor Cracks, Key Engineering Materials, 245, 2003,223-232.

19. R. Gasch, A Survey of the Dynamic Behaviour of a Simple Rotating Shaft with a Transverse Crack, Journal of Sound and Vibration, 160(2), 1993, 313-332.

20. G.D. Gounaris, C.A. Papadoloulos, Crack Identification in Rotating Shafts by Coupled Response Measurements, Engineering Fracture Mechanics,. 69, 2002, 339-352

21. S.C. Huang, Y.M. Huang, S.M. Shieh. Vibration and Stability of a Rotating Shaft Containing a Transverse Crack, Journal of Sound and Vibration, 162(3), 1993, 387-401

22. T. Inagaki, H. Kanki, and K. Shiraki, Transverse vibrations of a general crack-rotor bearing system, Journal of Mechanical Design, 104, 1982, 345-355.

23. Y. Ishida, T. Ikeda, T. Yamamoyo, and N. Masuda, Vibrations of a Rotating Shaft Containing a Transverse Crack, JSME International Journal, 31(1), 1988, 22-29.

24. O.S. Jun, H.J. Eun, Y.Y. Earmme, and C.W. Lee, Modelling and Vibration Analysis of a Simple Rotor with a Breathing Crack, Journal of Sound and Vibration, 155(2), 1992, 273-290.

25. C.W. Lee, J.S. Yun, and O.S. Jun, Modelling of a Simple Rotor with a Switching Crack and its Experimental Validation, Transactions of the ASME Journal of Vibration and Acoustics, 1992. 
26. H.D. Nelson and C. Nataraj, The Dynamics of a Rotor system with a Cracked Shaft, Journal of Vibration, Acoustics, Stress, and Reliability in design, 108, 1986, 189-196.

27. N. Pugno, C. Surace, and R. Ruotolo, Evaluation of the Non-linear Dynamic Response to Harmonic Excitation of a Beam with Several Breathing Cracks, Journal of Sound and Vibration, 235(5), 2000, 749-762.

28. R.H. Plaut, R.H. Andruet, and S. Suherman, Behaviour of a Cracked Rotating Shaft During Passage Through a Critical Speed, Journal of Sound and Vibration, 173(5), 1994, 577-589.

29. T.C. Tsai, and Y.Z. Wang, Vibration Analysis and Diagnosis of a Cracked Shaft, Journal of Sound and Vibration, 192(3), 1996, 607-620.

30. A.S. Sekhar, Vibration Characteristics of a Cracked Rotor with two Open Cracks, Journal of Sound and Vibration, 223(4), 1999, 497-512..

31. J-J. Sinou, and A.W. Lees, Influence of Cracks in Rotating Shafts, Journal of Sound and Vibration, 285(4-5), 2005, 1015-1037.

32. M.I. Friswell, and J.E. Mottershead, Finite Element Model Updating in Structural Dynamics. Kluwer Academic Publishers, 1995.

33. M. Lalanne, and G. Ferraris, Rotordynamics-Prediction in Engineering, John Wiley \& Sons, 1990.

34. A.H. Nayfeh, and D.T. Mook 1979 Nonlinear Oscillations, New-York : John Wiley \& Sons, 1979.

35. T.M.Cameron, and J.H. Griffin An Alternating Frequency/Time Domain Method for Calculating the Steady State Response of Nonlinear Dynamic. Journal of Applied Mechanics, 56, 1989, 149-154.

\begin{tabular}{cc}
\hline Parameters & Physical dimension \\
\hline Length of the shaft & $0.5 \mathrm{~m}$ \\
Diameter of the shaft & $0.01 \mathrm{~m}$ \\
Young's modulus of elasticity $E$ & $2.1 \times 10^{11} \mathrm{~N} \cdot \mathrm{m}^{-2}$ \\
Shear modulus $G$ & $7.7 \times 10^{10} \mathrm{~N} \cdot \mathrm{m}^{-2}$ \\
Poisson ratio $v$ & 0.3 \\
Density $\rho$ & $7800 \mathrm{~kg} \cdot \mathrm{m}^{-3}$ \\
Outer diameter of disc & $0.05 \mathrm{~m}$ \\
Inner diameter of disc & $0.01 \mathrm{~m}$ \\
Thickness of disc & $0.015 \mathrm{~m}$ \\
Masse unbalance & $0.01 \mathrm{~g}$ \\
Phase unbalance & 0 degree \\
Eccentricity of the mass unbalance & $0.01 \mathrm{~m}$ \\
Coefficient of damping $\beta$ & $2.10^{-5}$ \\
\hline
\end{tabular}

Table 1: Detail of the rotor parameters 


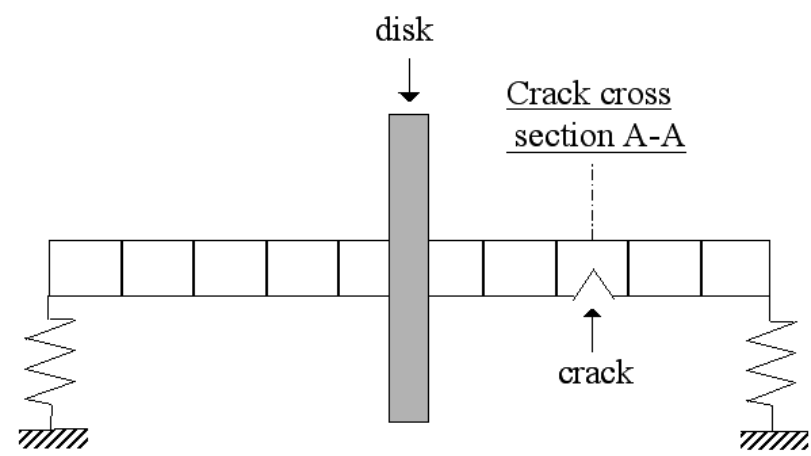

Crack cross section A-A

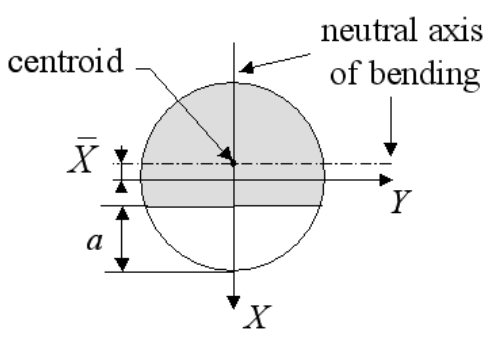

Shaft finite element

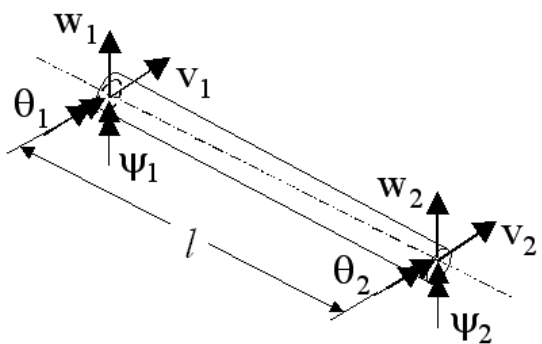

Figure 1: Rotor system and crack model cross-section
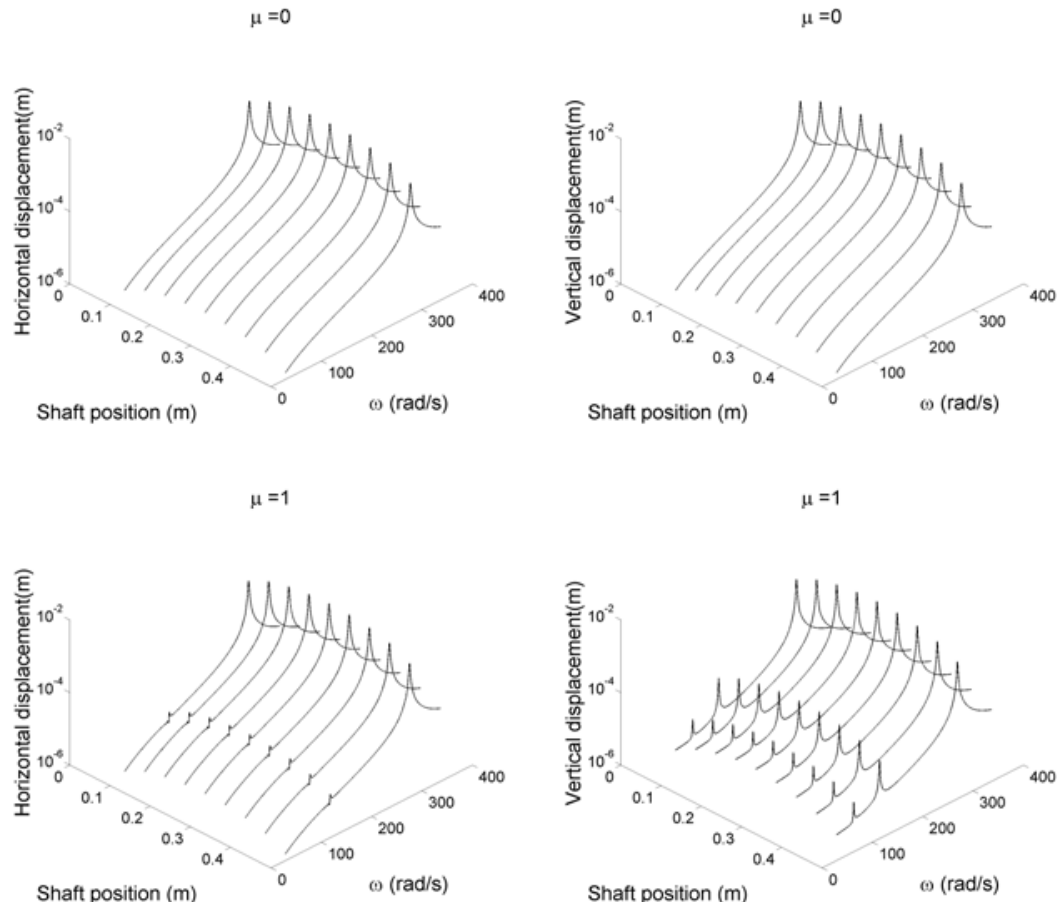

Figure 2: Comparisons between the uncracked and cracked responses 

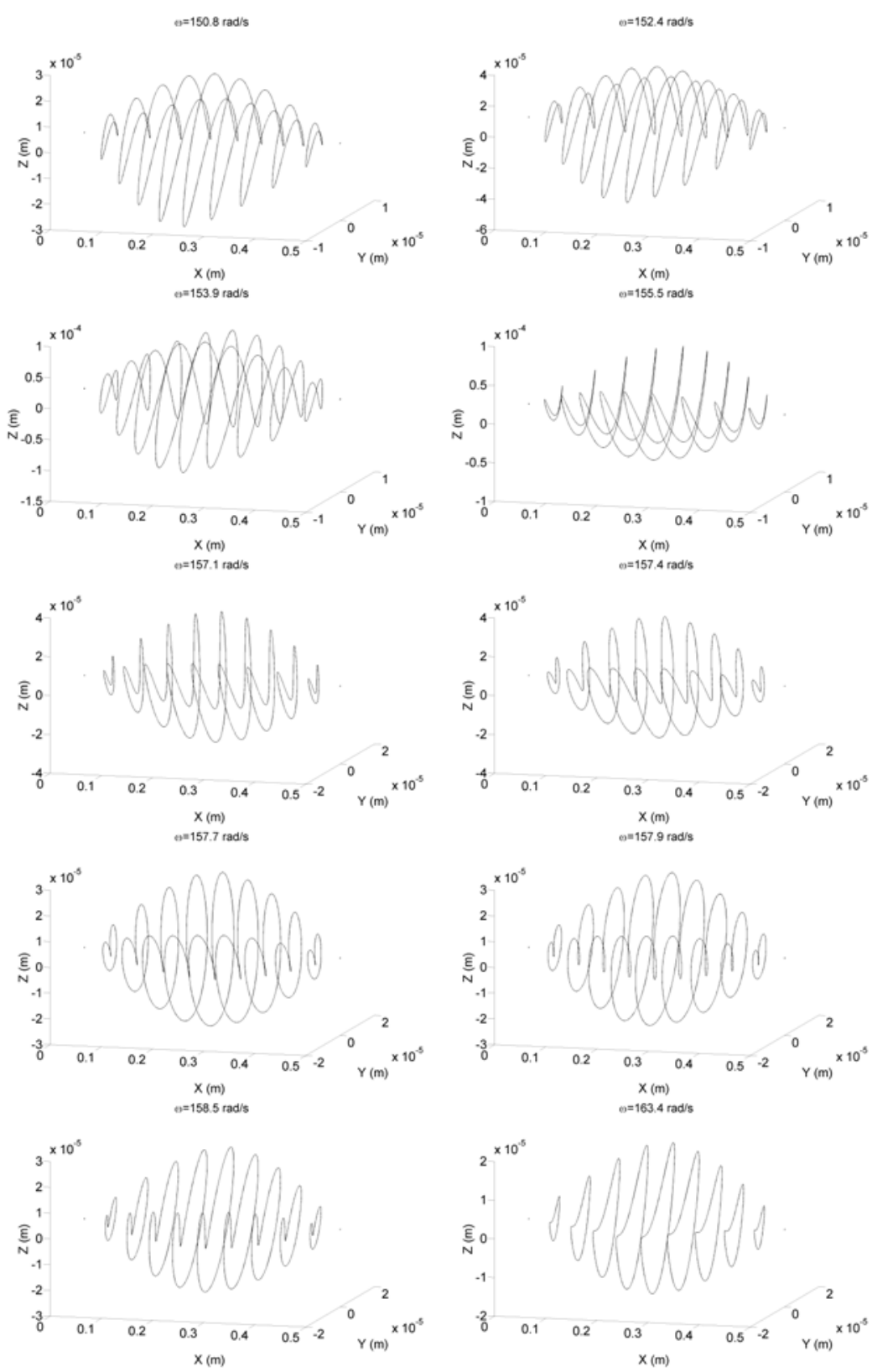

Figure 3 : evolution of the orbit over time at around one-half of the first critical speed 

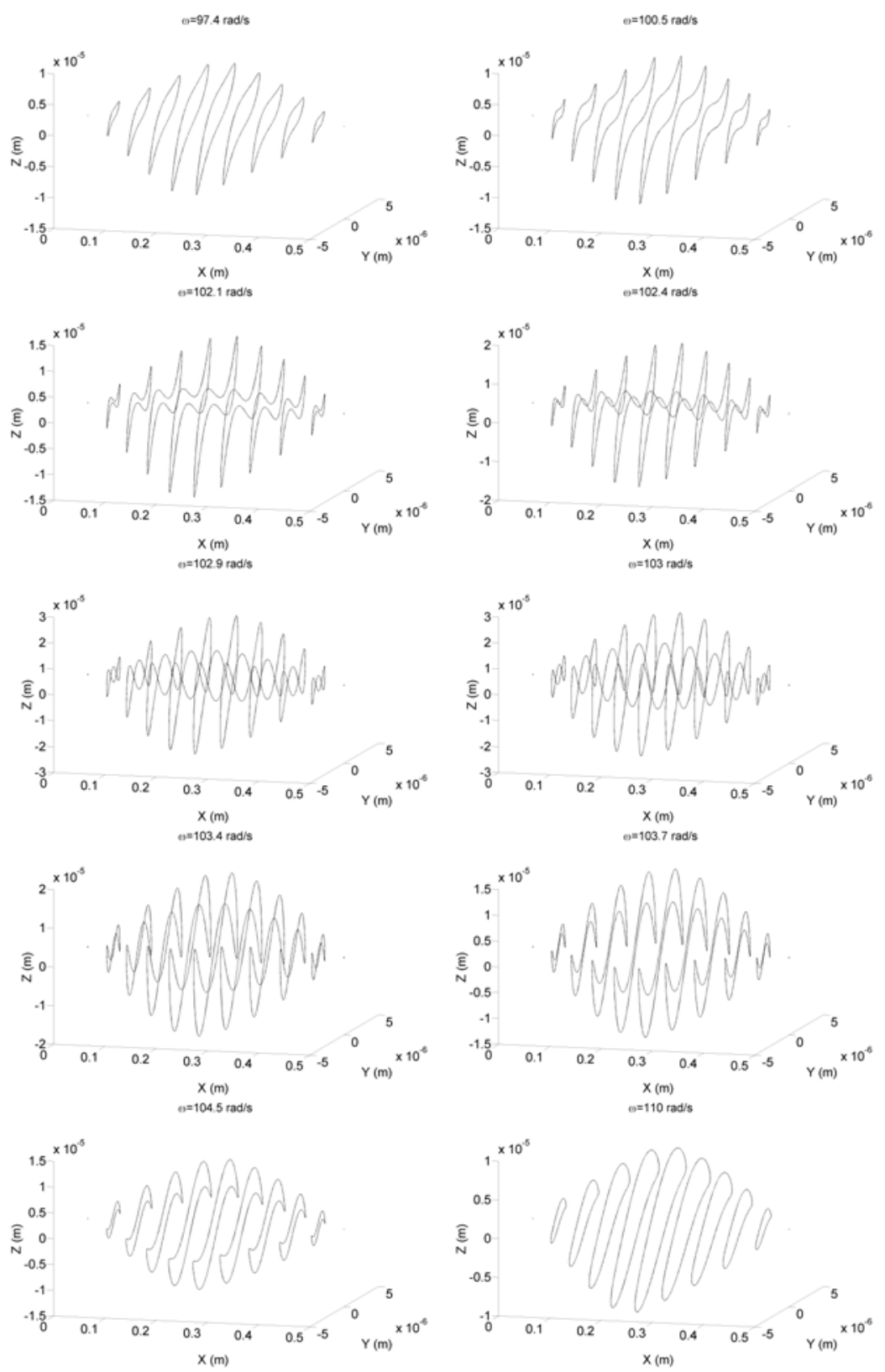

Figure 4: evolution of the orbit over time at around one-third of the first critical speed 

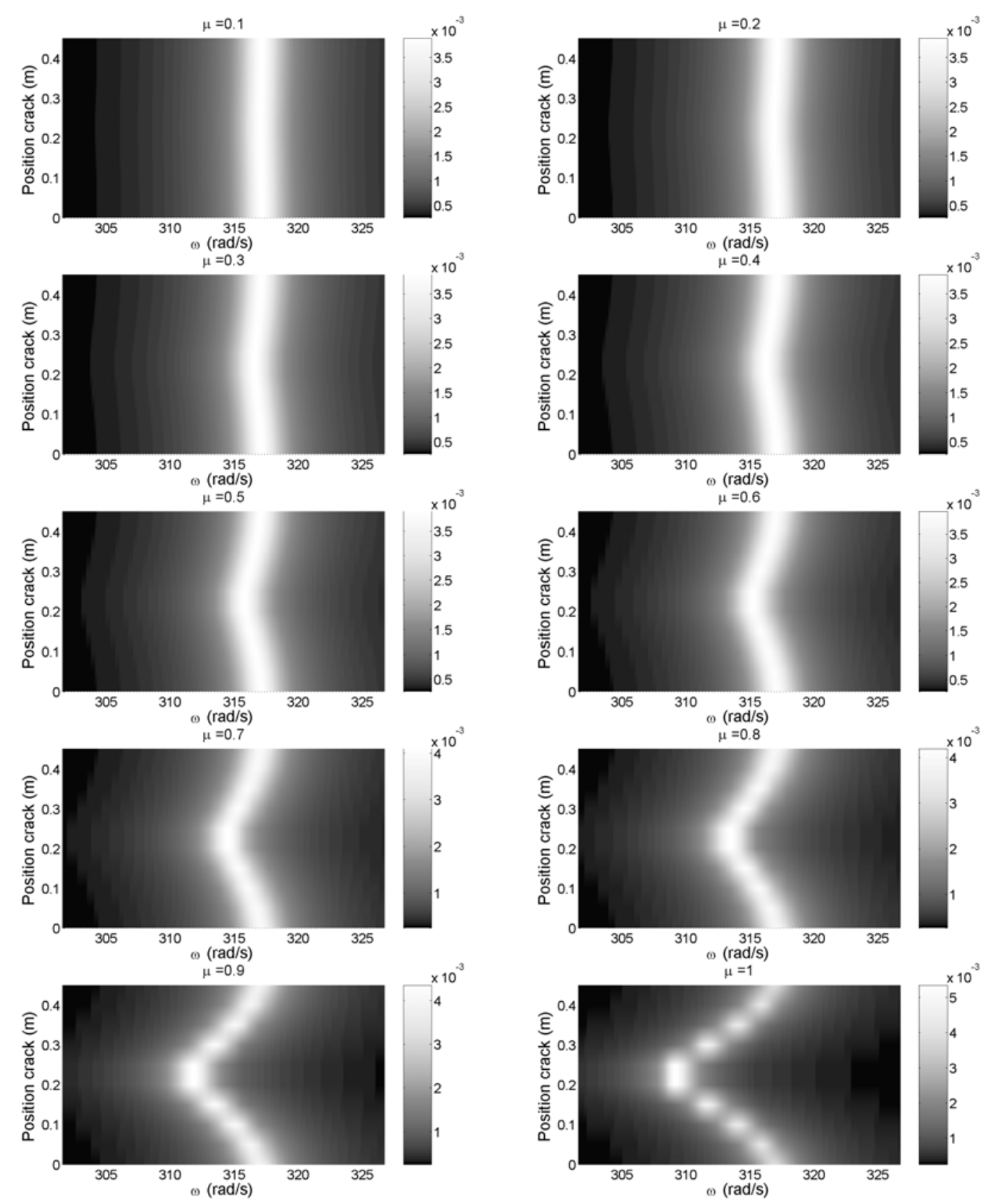

Figure 5: evolution of the vertical amplitude around the first critical speed at the middle of the shaft versus the crack position (for various crack depths) 


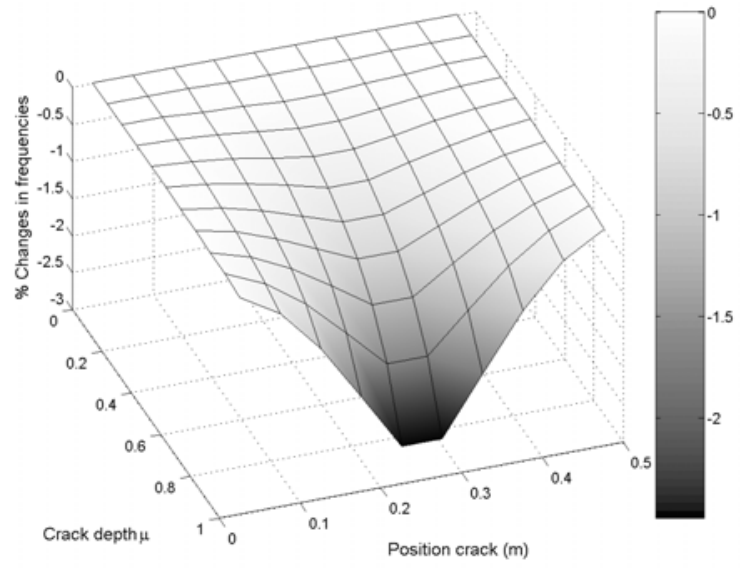

(a)

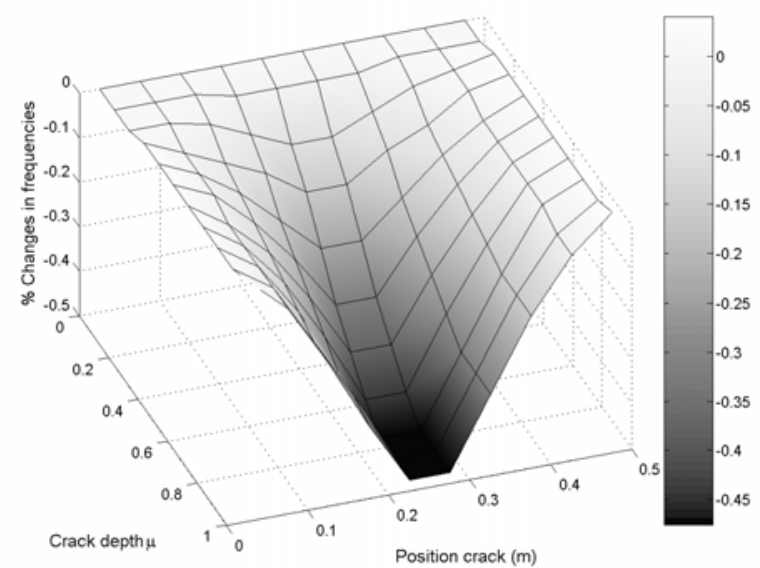

(b)

Figure 6: percentage changes in the first critical speed with the crack depth and the location of the crack (a)vertical displacements (b) horizontal displacements

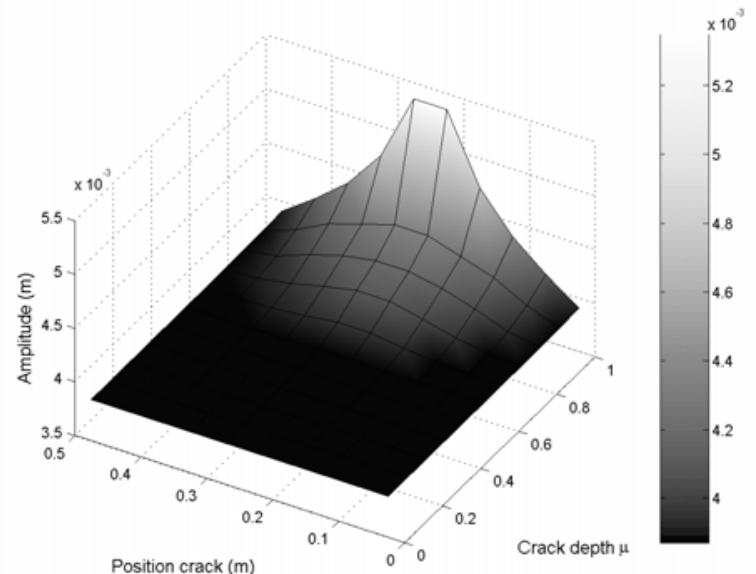

(a)

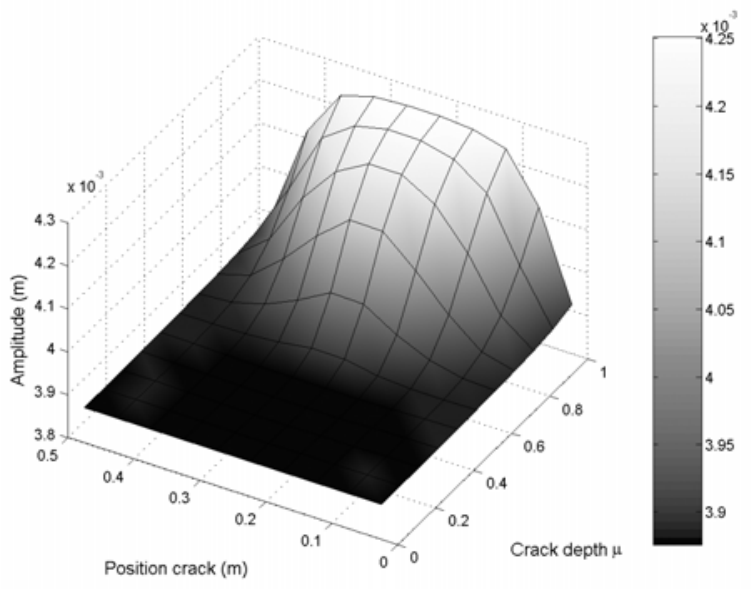

(b)

Figure 7: evolution of the maximum amplitude at the first critical speed with the crack depth and the location of the crack (a) vertical amplitude (b) horizontal amplitude 

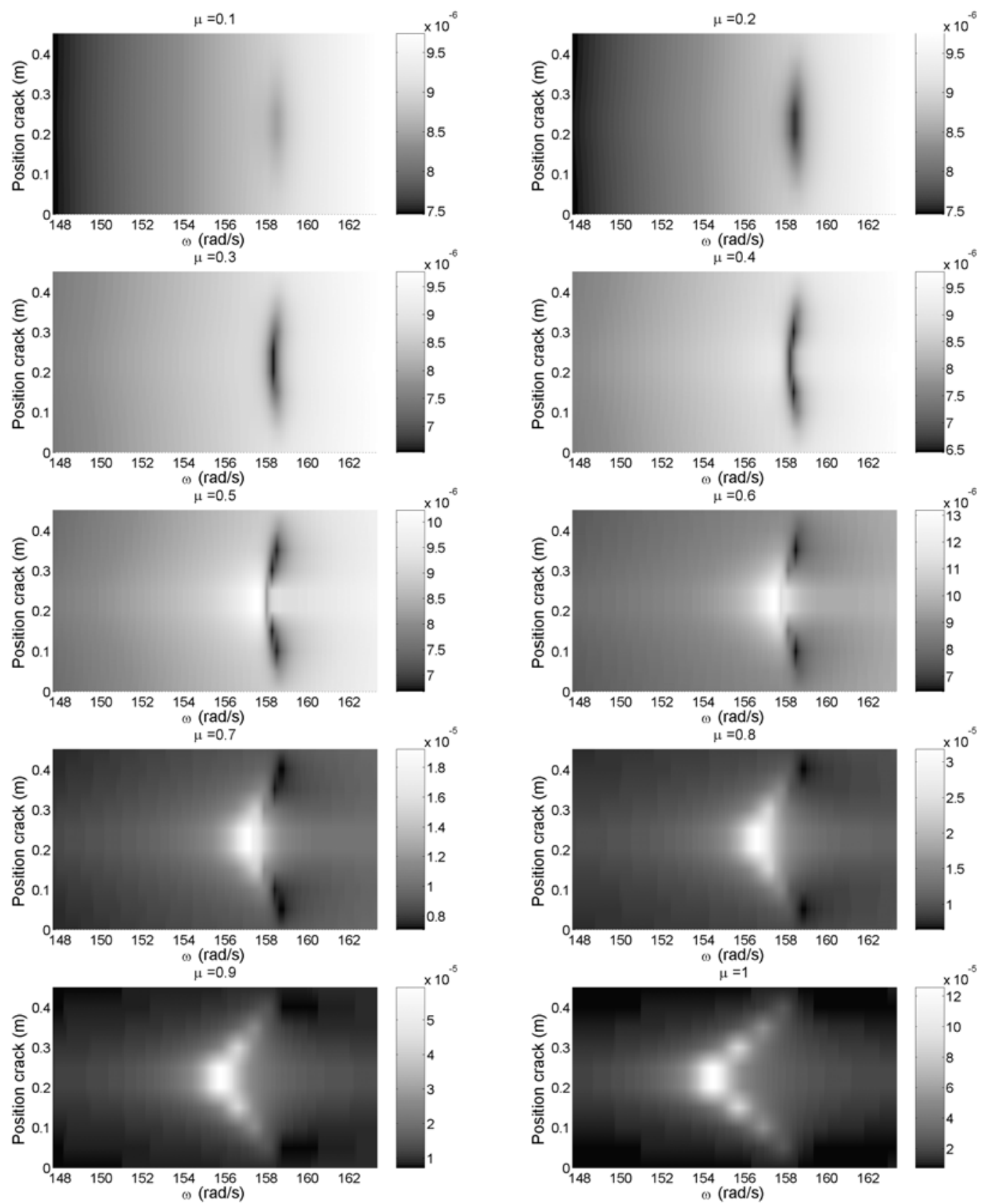

Figure 8: evolution of the vertical amplitudes for the middle of the rotor shaft around half of the first critical speed versus the crack position (for various crack depths) 


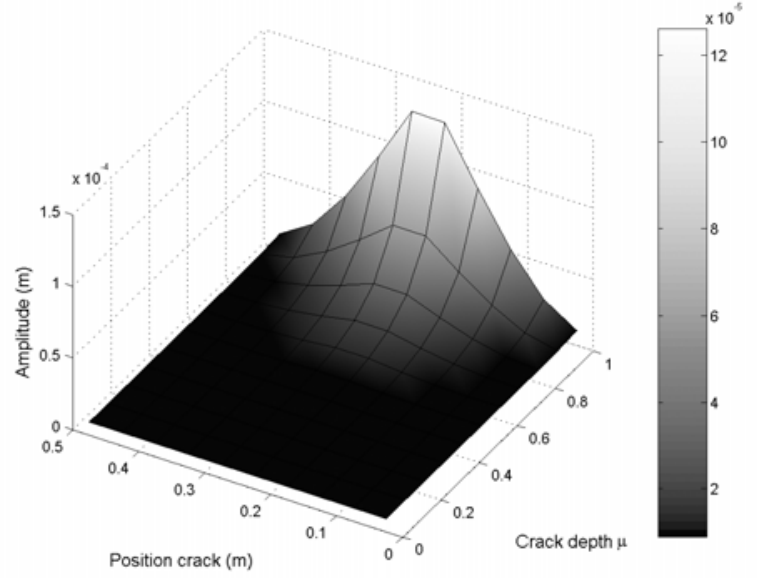

(a)

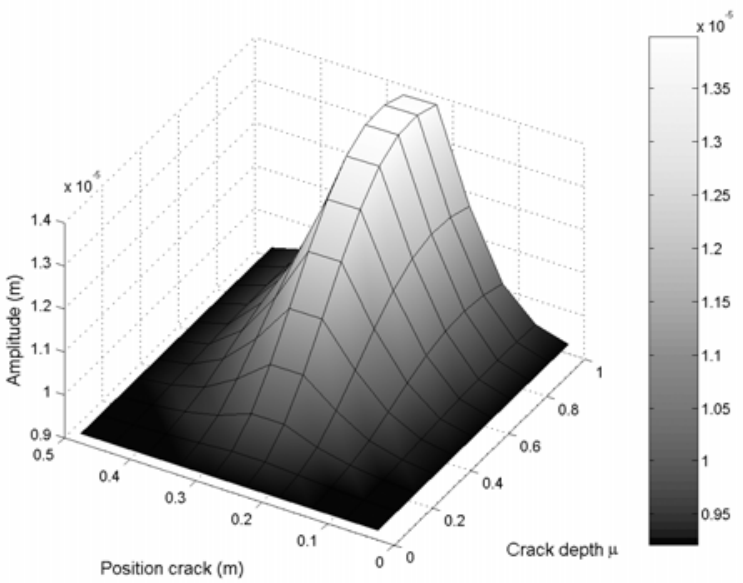

(b)

Figure 9: evolution of the maximum vertical amplitude at half of the first critical speed with the crack depth and the location of the crack (a) vertical amplitude (b) horizontal amplitude 

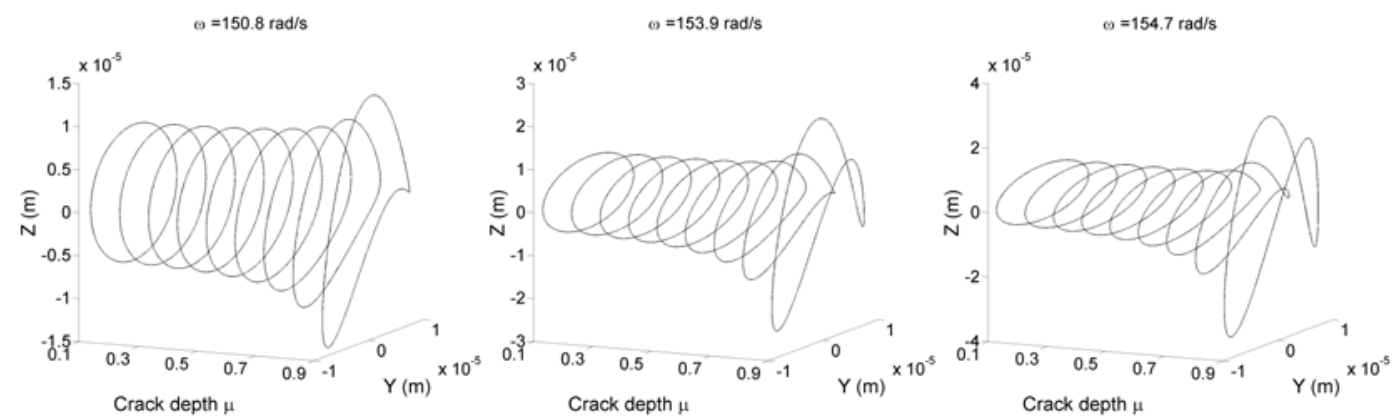

$\omega=155.5 \mathrm{rad} / \mathrm{s}$

$\omega=156.5 \mathrm{rad} / \mathrm{s}$

$\omega=157.1 \mathrm{rad} / \mathrm{s}$
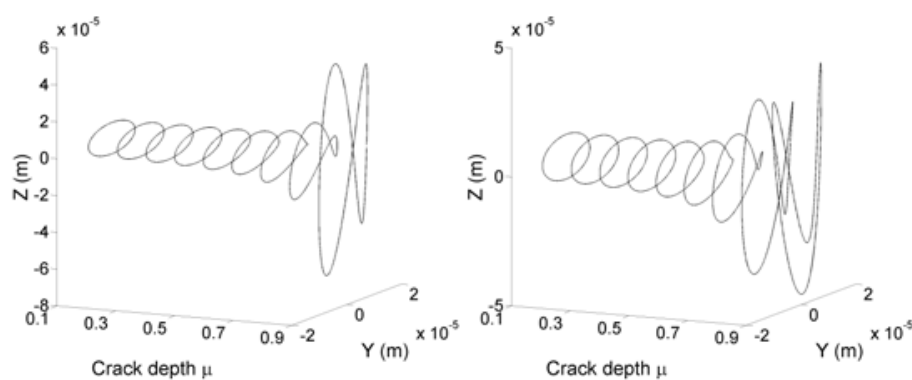

$\omega=157.7 \mathrm{rad} / \mathrm{s}$

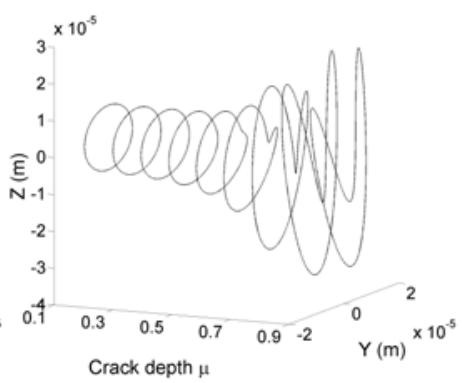

$\Theta=157.4 \mathrm{rad} / \mathrm{s}$

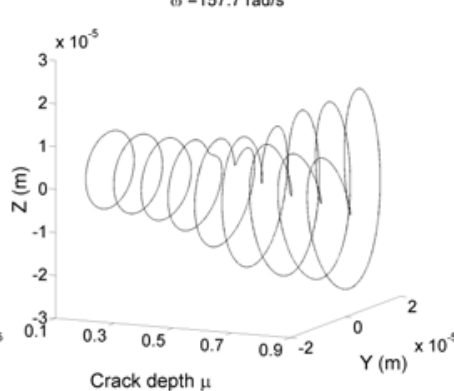

$\omega=158 \mathrm{rad} / \mathrm{s}$

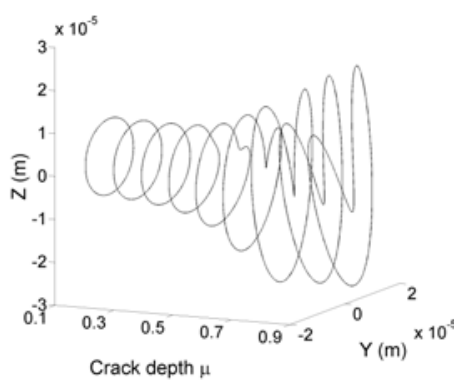

$\omega=158.3 \mathrm{rad} / \mathrm{s}$

$0=158.6 \mathrm{rad} / \mathrm{s}$

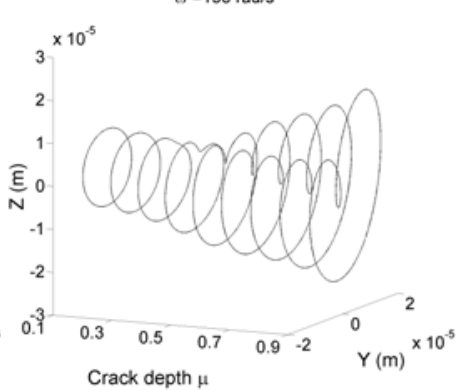

ck depth
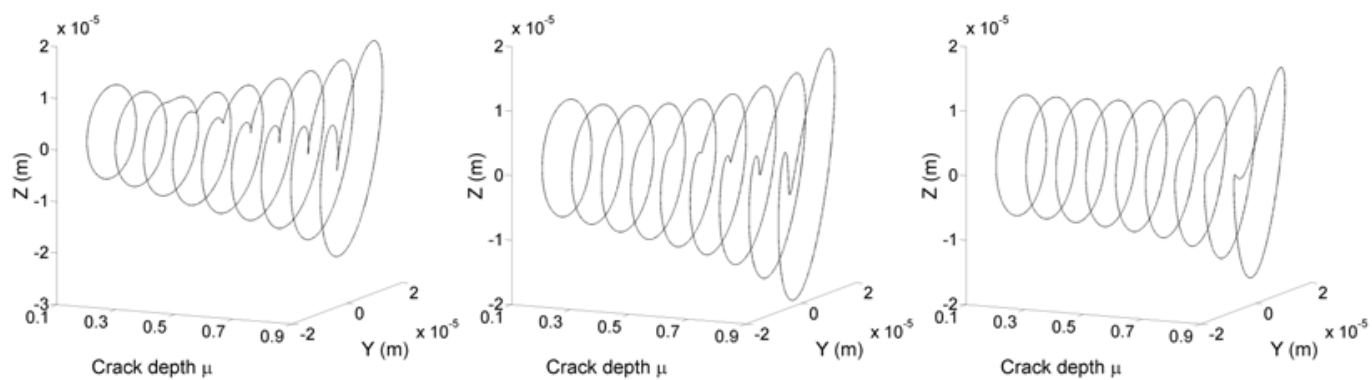

Figure 10: evolution of the orbits at the middle of the rotor shaft versus the non-dimensional crack depth 

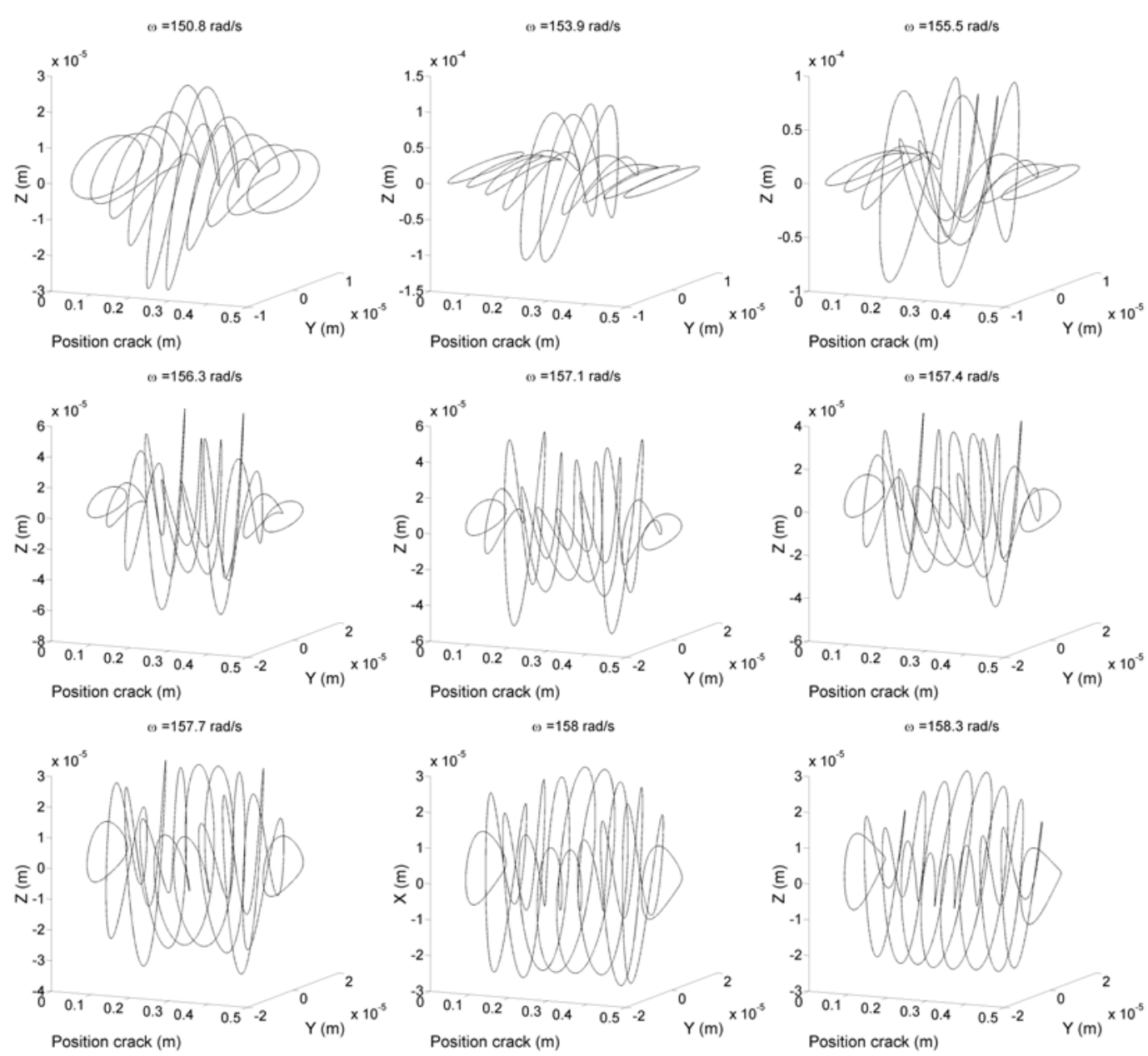

$\omega=158.7 \mathrm{rad} / \mathrm{s}$

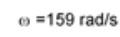

$\omega=160 \mathrm{rad} / \mathrm{s}$
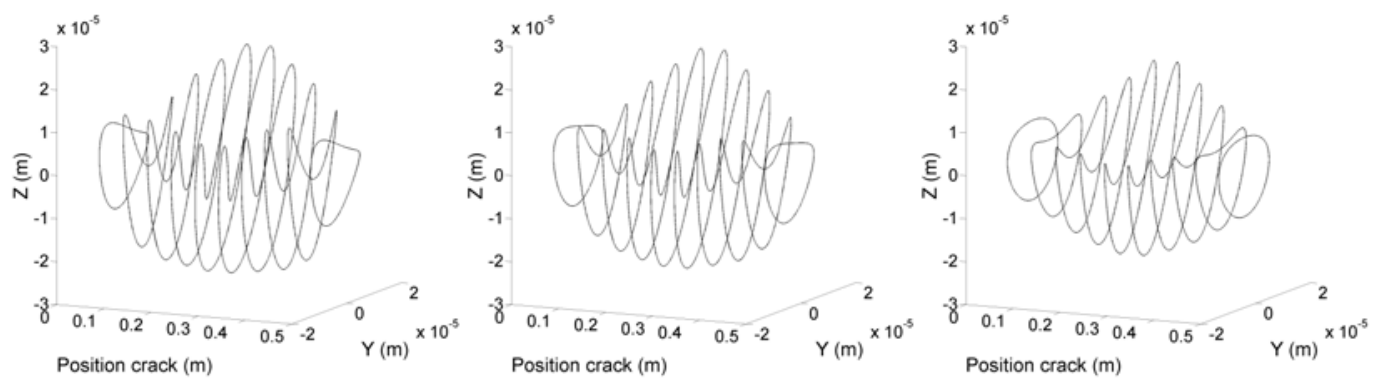

Figure 11 : evolution of the orbits at the middle of the rotor shaft versus the crack position 

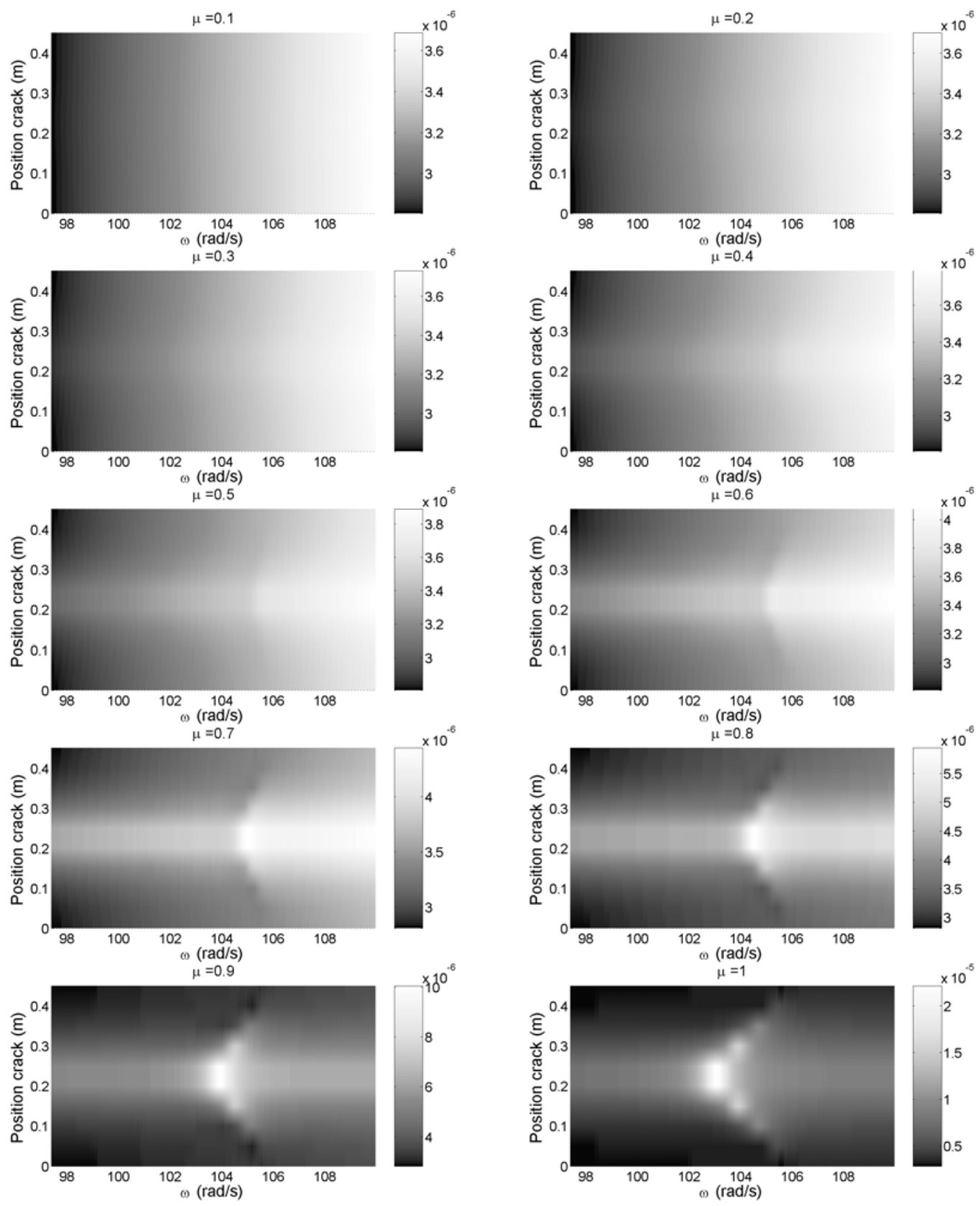

Figure 12: evolution of the horizontal amplitudes for the middle of the rotor shaft around one-third of the first critical speed versus the crack position (for various crack depths) 